\title{
Acute nutrient regulation of the unfolded protein response and integrated stress response in cultured rat pancreatic islets
}

\author{
H. Elouil • M. Bensellam • Y. Guiot • D. Vander Mierde • \\ S. M. A. Pascal • F. C. Schuit • J. C. Jonas
}

Received: 6 November 2006 / Accepted: 5 March 2007 / Published online: 12 May 2007

(C) Springer-Verlag 2007

\begin{abstract}
Aims/hypothesis Inadequate chaperone function relative to client protein load in the endoplasmic reticulum triggers an adaptive unfolded protein response (UPR), including the integrated stress response (ISR), the latter being also activated by other types of stresses. It is well established that pancreatic beta cells, which synthesise and secrete insulin upon nutrient stimulation, are markedly affected by pathological disruption or excessive activation of the UPR. However, whether and how physiological nutrient stimulation affects the beta cell UPR has been little investigated. Materials and methods We compared the effects of increasing glucose concentrations and of endoplasmic reticulum $\mathrm{Ca}^{2+}$ emptying with thapsigargin on the UPR (X-box binding protein $[\mathrm{Xbpl}]$ mRNA splicing and XBP1/ activating transcription factor [ATF] 6-target gene expression) and ISR (eukaryotic translation initiation factor 2A
\end{abstract}

Electronic supplementary material The online version of this article (doi:10.1007/s00125-007-0674-4) contains supplementary material, which is available to authorised users.

H. Elouil • M. Bensellam • S. M. A. Pascal · J. C. Jonas $(\square)$ Unit of Endocrinology and Metabolism, Faculty of Medicine,

Université Catholique de Louvain,

Avenue Hippocrate, 55 (UCL 55.30),

1200 Brussels, Belgium

e-mail: jonas@endo.ucl.ac.be

Y. Guiot

Service of Pathology, Faculty of Medicine,

Université Catholique de Louvain,

Brussels, Belgium

D. Vander Mierde $\cdot$ F. C. Schuit

Gene Expression Unit, Department of Molecular Cell Biology,

Katholiek Universiteit Leuven,

Leuven, Belgium phosphorylation, ATF4 protein levels and target gene expression) in isolated rat islets.

Results Thapsigargin strongly increased both UPR and ISR. In comparison, glucose moderately increased the UPR between 5 and $30 \mathrm{mmol} / \mathrm{l}$, but exerted complex effects on the ISR as follows: (1) marked reduction between 2 and $10 \mathrm{mmol} / \mathrm{l}$; (2) moderate increase parallel to the UPR between 10 and $30 \mathrm{mmol} / \mathrm{l}$. These glucose effects occurred within $2 \mathrm{~h}$, were mimicked by other metabolic substrates, but were independent of changes in $\mathrm{Ca}^{2+}$ influx or insulin secretion. Remarkably, attenuating the glucose stimulation of protein synthesis with a low concentration of cycloheximide prevented UPR activation but not ISR reduction by high glucose.

Conclusions/interpretation Nutrient stimulation acutely activates rat islet UPR in a manner dependent on protein synthesis, while exerting complex effects on the ISR. These effects may contribute to nutrient-induced maintenance of the beta cell phenotype.

Keywords Beta cell - Endoplasmic reticulum stress . Gene expression - Integrated stress response . $\alpha$-Ketoisocaproate $\cdot$ Nutrient stimulation · Pancreatic islet . Protein synthesis · Succinic acid - Unfolded protein response

\begin{tabular}{|c|c|}
\hline \multicolumn{2}{|c|}{ Abbreviations } \\
\hline ATF & activating transcription factor \\
\hline $\mathrm{BiP}$ & immunoglobulin heavy chain binding protein \\
\hline $\begin{array}{l}\text { EDEM } \\
\text { eIF2 } \alpha\end{array}$ & $\begin{array}{l}\text { ER-degradation enhancer mannosidase alpha-like } 1 \\
\text { eukaryotic translation initiation factor } 2 \mathrm{~A}\end{array}$ \\
\hline ER & endoplasmic reticulum \\
\hline G10 & $\begin{array}{l}10 \mathrm{mmol} / 1 \text { glucose }(\mathrm{G} 2, \mathrm{G} 5, \mathrm{G} 30 \text { for } 2,5 \text {, } \\
30 \mathrm{mmol} / 1 \text { glucose })\end{array}$ \\
\hline GADD & growth arrest and DNA damage \\
\hline GRP & glucose regulated protein \\
\hline RE & inositol requiring \\
\hline
\end{tabular}


ISR integrated stress response

KIC $\quad \alpha$-ketoisocaproate

SAM succinic acid monomethyl ester

PERK pancreatic ER kinase

UPR unfolded protein response

XBP X-box binding protein

\section{Introduction}

Folding of proteins destined for the secretory pathway in the endoplasmic reticulum (ER) critically depends on adequate production and function of ER chaperones such as immunoglobulin heavy chain binding protein (BiP; now known as heat shock $70 \mathrm{kDa}$ protein 5 [glucose-regulated protein] [HSPA5]), glucose-regulated protein (GRP) 94 (now known as heat shock protein $90 \mathrm{kDa}$ beta, member 1 [HSP90B1]), calnexin, calreticulin and protein disulphide isomerase [1]. When ER chaperone function decreases or ER client protein load increases (following ER $\mathrm{Ca}^{2+}$ emptying, ATP depletion, increased protein synthesis, etc.), the unfolded protein response (UPR) is activated. This transiently reduces protein synthesis, improves the cell capacity to fold proteins and degrade unfolded proteins and increases cellular defences against various types of stresses [2-4]. This response, which is controlled by the ER stress sensors inositol requiring (IRE) 1, activating transcription factor (ATF) 6 and pancreatic ER kinase (PERK; now known as EIF2A kinase 3 [EIF2AK3]), consists of two branches. The first branch results from the unconventional splicing of X-box binding protein $1(X b p l)$ pre-mRNA by IRE1, with a subsequent increase in active XBP1, and from the proteolytic activation of ATF6. Both transcription factors contribute to increase the production of ER chaperones such as BiP and GRP94, as well as of components of the ER-associated degradation pathway like ER degradationenhancer mannosidase alpha-like 1 (EDEM) [5]. The second branch results from phosphorylation of the eukaryotic translation initiation factor 2 alpha (eIF2 $\alpha$; now known as EIF2A) on $\mathrm{Ser}^{51}$ by PERK, followed by a general translational pause with selective increase in Atf4 mRNA translation and subsequent stimulation of expression of ATF4-target genes like Atf3, growth arrest and DNA damage (Gadd)153 (now known as DNA-damage-inducible transcript 3 [Ddit3], also known as Chop), Gadd34 (now known as protein phosphatase 1 , regulatory [inhibitor] subunit 15A [Ppp1r15a]) and BiP [6]. Because eIF2 $\alpha$ $\mathrm{Ser}^{51}$ can also be phosphorylated by other kinases (EIF2AK1, 2 and 4) independently of UPR activation, events downstream from eIF $2 \alpha-$ Ser $^{51}$ phosphorylation (the shared branch of the UPR as defined by Ma et al. [7]) will be referred to here as the integrated stress response (ISR) regardless of the kinase involved [7-9].
Pancreatic beta cells, which synthesise and secrete insulin in a manner dependent on glucose concentration [10], produce high levels of several UPR and ISR components. Surprisingly, both genetic disruption and excessive activation of the UPR and ISR induce beta cell apoptosis and type 1 diabetes [11-14] (recently reviewed in [4]), suggesting that survival and function of beta cells critically depend on a continuous physiological activation of the UPR to cope with their high rate of proinsulin synthesis. More recently, it was also demonstrated that prolonged exposure to palmitate or high glucose concentrations triggers an ER stress response in insulin-secreting INS1 cells [15-17], suggesting that ER stress may play a role in beta cell gluco-lipotoxicity in type 2 diabetes.

Glucose is the main physiological regulator of protein synthesis in beta cells. As such, it can be expected to activate the UPR and ISR to compensate for an increase in ER client protein load. In support of that hypothesis, it was recently demonstrated that glucose acutely induces IRE1 $\alpha$ phosphorylation and UPR activation in isolated mouse islets [18]. However, these effects were not accompanied by Xbpl mRNA splicing, a hallmark of UPR activation [19]. In contrast, it has recently been shown that glucose rapidly decreases eIF $2 \alpha$ phosphorylation and the ISR in MIN6 cells $[20,21]$. To investigate whether and to what extent physiological nutrient stimulation affects the UPR in normal beta cells, we tested the effects of increasing glucose concentrations and of other metabolic substrates on the UPR and ISR in cultured rat islets, and compared these effects to those of the specific inhibitor of sarcoendoplasmic reticulum $\mathrm{Ca}^{2+}$-ATPases, thapsigargin, which is a potent inducer of ER stress in many cell types [3].

\section{Materials and methods}

Materials Thapsigargin, cycloheximide, succinic acid monomethyl ester (SAM), $\alpha$-ketoisocaproate (KIC), Lglutamine and diazoxide were purchased from Sigma ( $\mathrm{St}$ Louis, MO, USA). L-Leucine was from Calbiochem (San Diego, CA, USA).

Antibodies Rabbit polyclonal anti-GADD153 (sc-575), anti-ATF4 (sc-200) and anti-XBP1 (sc-7160) antibodies were from Santa Cruz Biotechnologies (Santa Cruz, CA, USA). Mouse anti-BiP antibody (clone 40) was from BD Biosciences (San Diego, CA, USA). Rabbit polyclonal antiACTIN antibody was from Sigma. Mouse monoclonal antitotal-eIF $2 \alpha$ antibody was provided by D. Scheuner (Howard Hughes Medical Institute, University of Michigan, MI, USA). Rabbit anti-phospho-eIF2 $\alpha$ antibodies were generated as described previously [20]. 
Islet isolation and culture Islets were isolated from the pancreas of $200 \mathrm{~g}$ male Wistar rats (local animal facility), as described previously [22]. They were precultured for 1 week at $37^{\circ} \mathrm{C}$, in the presence of $5 \% \mathrm{CO}_{2}$, in serum-free RPMI-1640 medium (Gibco, Grand Island, NY, USA) containing $10 \mathrm{mmol} / 1$ glucose (G10), $5 \mathrm{~g} / 1$ BSA fraction $\mathrm{V}$ (Roche, Basel, Switzerland), $100 \mathrm{IU} / \mathrm{ml}$ penicillin and $100 \mu \mathrm{g} / \mathrm{ml}$ streptomycin. Large islets (diameter $>150 \mu \mathrm{m}$ ) were discarded. After preculture, islets were further cultured in medium containing $2-30 \mathrm{mmol} / 1$ glucose (G2, G5, G10 or G30) and various test substances, then collected for further analysis. All experiments were conducted in accord with accepted standards of humane animal care and were approved by the local Institutional Committee on Animal Experimentation.

RNA extraction and cDNA synthesis Islet total RNA was extracted and reverse-transcribed in cDNA as described [22].

Measurement of Xbp1 mRNA splicing cDNAs corresponding to the unspliced and spliced forms of $X b p 1$ mRNA (NM_001004210) were amplified simultaneously with TATA-box binding protein $(\mathrm{Tbp})$ cDNA by duplex radioactive PCR $[19,22]$ (see Electronic supplementary material [ESM] Table 1). The spliced:total Xbpl mRNA ratio was calculated as an indicator of $X b p 1$ mRNA splicing.

Real-time fluorescent PCR Real-time PCR was performed as described elsewhere [23] (ESM Table 2). Within each PCR, sample threshold cycles were compared with a standard curve prepared by serial fourfold dilutions of an appropriate control cDNA. Relative changes in gene mRNA levels were expressed relative to the mRNA levels in control islets and normalised for relative changes in $T b p$ mRNA levels.

Western blotting After rinsing with ice-cold PBS, islets were precipitated with trichloracetic acid and their proteins were solubilised in Laemmli buffer. For eIF $2 \alpha$ phosphorylation measurements, islet protein extracts were prepared as described previously [20]. Proteins were separated by $8-12 \%$ SDS-PAGE and electrophoretically transferred to nitrocellulose membranes. The membrane was blocked (5\% non-fat dry milk in Tris-buffered saline [pH 7.4] containing $0.05 \%$ Tween-20), incubated overnight with the primary antibody, washed, incubated for $1 \mathrm{~h}$ with a horseradish peroxidaseconjugated anti-rabbit or anti-mouse antibody and washed before detection of bound antibodies by enhanced chemiluminescence. Band intensities were quantified by scanning densitometry and normalised to Rouge Ponceau staining intensity.

GADD153 immunohistochemistry Islets were washed, fixed in $1 \%$ formaldehyde and embedded in paraffin. Then,
GADD153 was detected on $5 \mu \mathrm{m}$ thick sections using antiGADD153 antibody diluted 1:800 and the procedure described previously for haem oxygenase 1 immunodetection [22].

Measurement of protein biosynthesis Islet protein synthesis was estimated from the incorporation of $\mathrm{L}-\left[3,5-{ }^{3} \mathrm{H}\right]$ tyrosine (Amersham Biosciences, Bucks, UK) in total islet protein extracts during culture, as previously described [24].

Insulin secretion measurements Insulin concentrations in the culture media were determined by RIA using rat insulin as a standard [25]. The amount of insulin secreted during the whole culture period was expressed in pmol islet ${ }^{-1} \mathrm{~h}^{-1}$.

Data analysis The results are presented as means \pm SEM for the indicated number of experiments. In all cases, gene mRNA and protein levels were expressed relative to the level measured in the group of islets that had been maintained under the same condition as in the last $24 \mathrm{~h}$ of preculture (most frequently G10).

\section{Results}

Most experiments were carried out in islets precultured for 1 week in serum-free RPMI medium containing G10 and $5 \mathrm{~g} / 1$ BSA. These islets, which have recovered from the stress of isolation [26], have a well-preserved morphology and beta cell glucose responsiveness with low level of beta cell apoptosis [27], in marked contrast with islets cultured for several days in G5 [28]. They express total Xbp 1, BiP and Grp 94 mRNA at much higher levels than Tbp, and Edem, Atf3, Gadd153 and Gadd34 mRNA at similar or lower levels (ESM Table 2).

Effects of thapsigargin and increasing glucose concentrations on the UPR and the ISR in isolated islets We first tested the effects of $18 \mathrm{~h}$ of culture in the presence of $10^{-8}-10^{-6} \mathrm{~mol} / \mathrm{l}$ thapsigargin. As shown in Fig. 1, thapsigargin dose-dependently increased insulin secretion, $X b p 1$ mRNA splicing and mRNA levels of BiP, Grp94, Edem, Atf3, Gadd153 and Gadd34, without affecting total Xbp1 and Tbp mRNA levels. Thapsigargin also significantly increased islet XBP1, ATF4, BiP and GADD153 protein levels (Fig. 2), the latter being detected in most islet cell nuclei (Fig. 2f). The increase in Xbpl mRNA splicing was maximal within 2 h, while Gadd153 mRNA levels steadily increased during the first $8 \mathrm{~h}$ of thapsigargin treatment (data not shown). Thus, emptying $\mathrm{ER} \mathrm{Ca}^{2+}$ with thapsigargin rapidly and strongly activates both UPR and ISR in rat islet cells. 
Fig. 1 Effects of thapsigargin $(T G)$ and increasing glucose concentrations on insulin secretion during culture $(\mathbf{a}, \mathbf{b})$; spliced : total $X b p 1$ mRNA ratio (c, d); and the mRNA levels of total $X b p 1$ (e, f), BiP (open circles), Grp94 (filled circles), Edem (open squares) (g, h), and (i, j) Atf3 (open circles), Gadd153 (closed circles) and Gadd34 (open squares) in isolated rat islets. After 1 week of preculture in G10, the islets were cultured for $18 \mathrm{~h}$ in G10 plus increasing thapsigargin concentrations (a, c, e, g, i) or in $\mathrm{G} 2, \mathrm{G} 5, \mathrm{G} 10$ and $\mathrm{G} 30(\mathbf{b}, \mathbf{d}, \mathbf{f}, \mathbf{h}, \mathbf{j})$. Gene : $T b p$ mRNA ratios are expressed relative to the ratio in islets cultured in G10. Data are means \pm SEM for three thapsigargin and seven glucose experiments. ${ }^{*} p \leq 0.05$ vs islets cultured in G10 (oneway ANOVA + Newman-Keuls test). ${ }^{\#} p$ values for comparison of G30 vs G10 mRNA levels by unpaired $t$ test: 0.008 for BiP, 0.007 for Grp94, 0.005 for Edem, 0.036 for Atf3, 0.003 for Gadd153 and 0.007 for Gadd 34 . j, Please note the logarithmic scale on the $y$-axis

We next tested the effects of a decrease or increase in glucose concentration. As shown in Fig. 1, $18 \mathrm{~h}$ culture in G2-G5 vs G10 resulted in a significant decrease in insulin secretion and $X b p 1$ mRNA splicing, the latter being always significantly higher than zero $(p<0.0001$ by one sample $t$ test). There were no changes in total Xbpl, Grp94, Edem and $T b p$, and a strong increase in Atf3, Gadd153 and Gadd34 mRNA levels. The latter effect only partly resulted from a $\sim 2.3$-fold increase in Atf3 and Gadd153 mRNA half-life in G2 vs G10 (ESM Fig. 1). Under these conditions, XBP1 protein levels decreased in G5 vs G10 while BiP and GADD153 protein levels increased in both G5 and G2 (Fig. 2). In G2, GADD153 increased in most islet cell nuclei (Fig. 2d). Clear increases in BiP mRNA and ATF4 protein levels were only observed in G2 vs G10 (Figs. 1h and 2a,c). Thus, lowering glucose from G10 to G5 and G2 attenuates the UPR while increasing mRNA of genes involved in ISR and corresponding protein levels.

In contrast with culture in low glucose, $18 \mathrm{~h}$ culture in G30 vs G10 induced a significant increase in insulin secretion, Xbp1 mRNA splicing and XBP1 protein levels without changes in total $X b p 1$ and $T b p$ mRNA levels (Fig. 1b,d,f,h,j, Fig. 2a,b). High glucose also induced a small similar increase in BiP, Grp94, Edem, Atf3, Gadd153 and Gadd34 mRNA levels (Fig. 1h,j). Under these conditions, culture in G30 vs G10 significantly increased BiP, but neither ATF4 nor GADD153 protein levels (Fig. 2b,c). When the islets were cultured for 1 week in G10 or G30 immediately after isolation, the spliced : total $X b p 1$ mRNA ratio was also significantly increased (from $0.18 \pm 0.03$ in G10 to $0.24 \pm 0.02$ in $\mathrm{G} 30 ; n=7 ; p<0.05$ by unpaired $t$ test). Thus, increasing glucose from G10 to G30 for $18 \mathrm{~h}$ up to 1 week moderately activates the UPR and increases mRNA levels of genes involved in ISR in cultured rat islets.

Altogether, these results suggest that, in contrast to thapsigargin, which strongly increases both UPR and ISR, glucose moderately increases the UPR between G5 and G30 but exerts complex effects on the ISR, namely a marked reduction from $\mathrm{G} 2$ to $\mathrm{G} 10$, and a moderate increase a

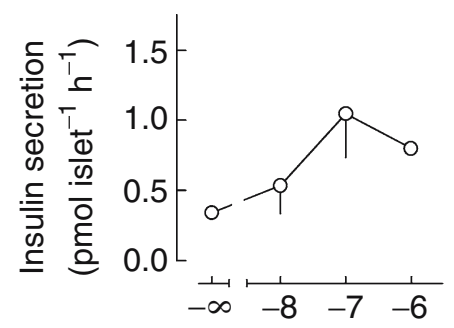

C

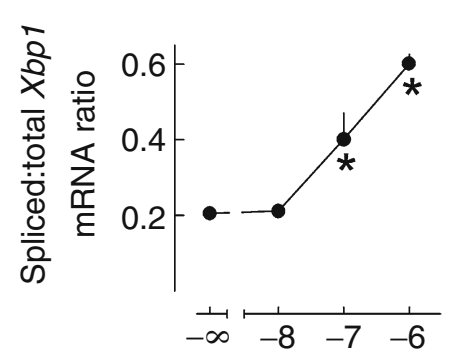

e

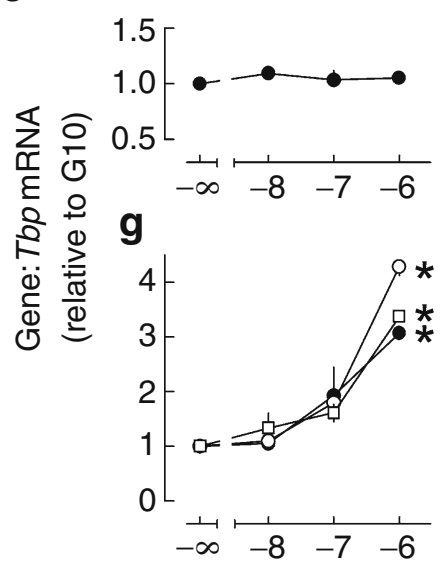

i

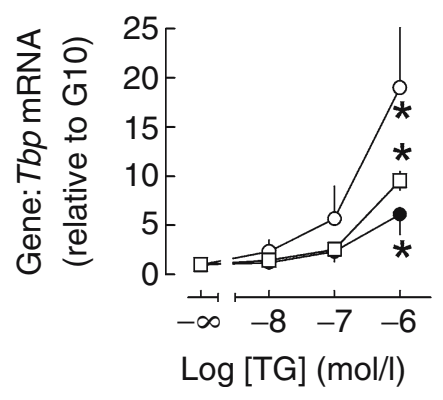

b

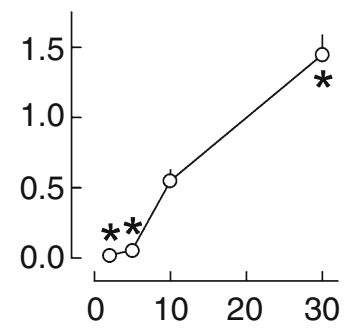

d

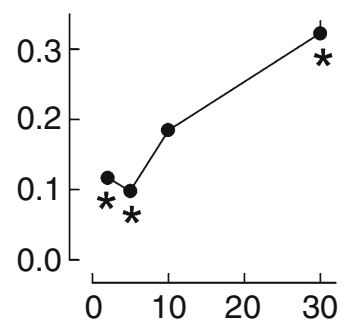

f

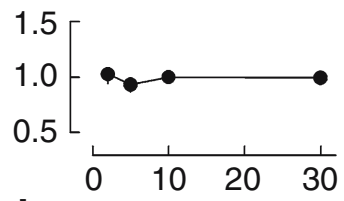

h

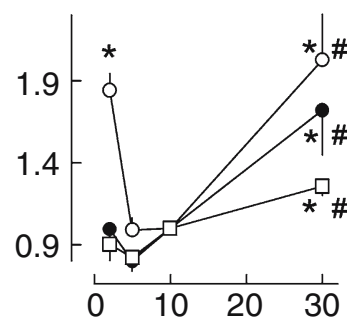

j

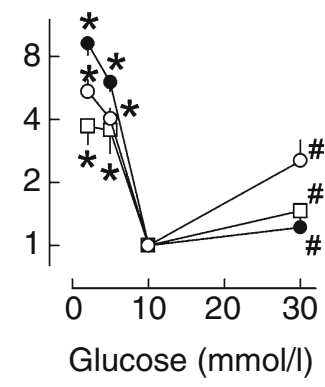

parallel to the UPR from G10 to G30. The effects of glucose on Xbpl mRNA splicing and Gadd153 mRNA levels were similar in medium containing $10 \%$ FCS instead of BSA (data not shown).

Time-dependence of the effects of glucose on the UPR We next tested the kinetics of UPR regulation by glucose between G5 and G30. After $18 \mathrm{~h}$ culture in G5, the rate of 

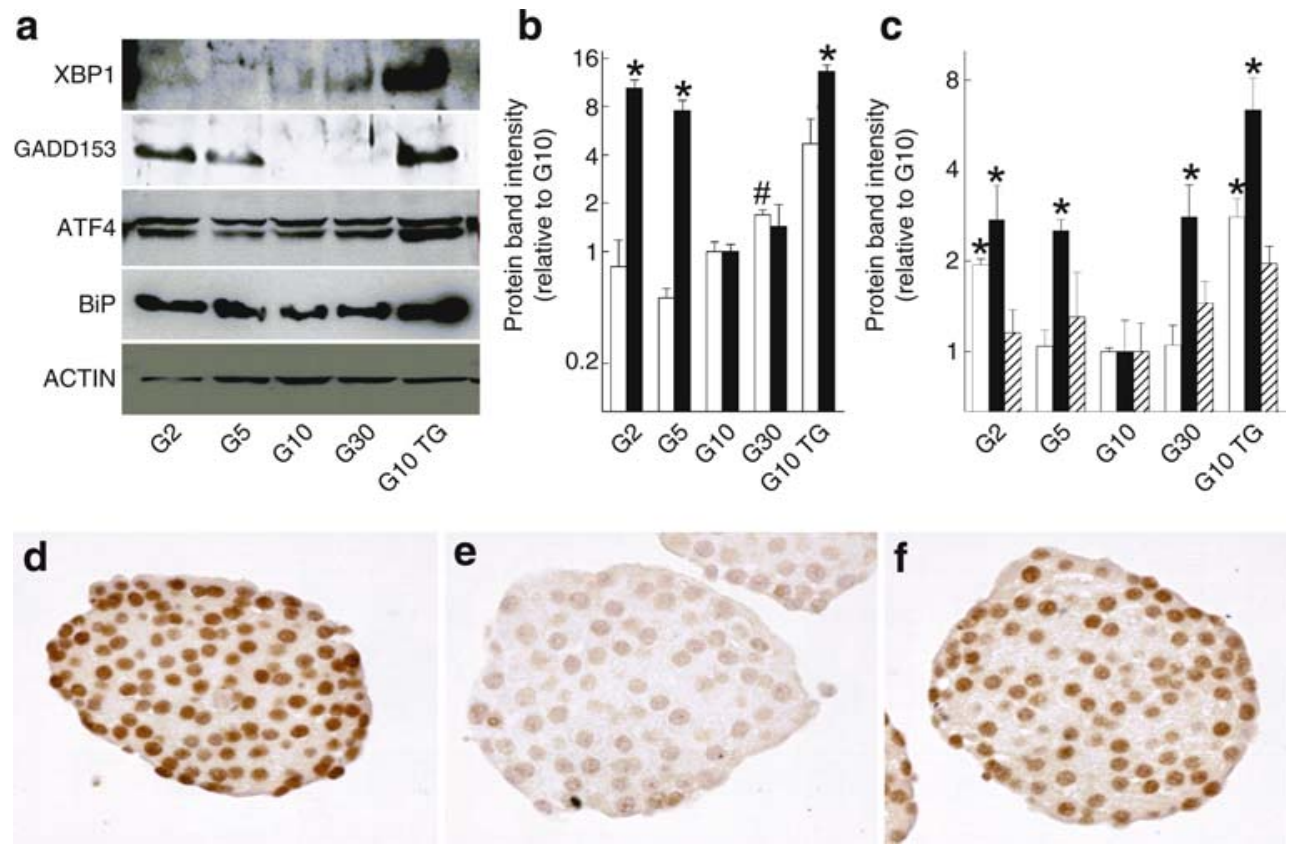

Fig. 2 Effects of increasing glucose concentrations and thapsigargin $(T G)$ on XBP1, GADD153, ATF4, BiP and ACTIN protein levels in cultured rat islets. After 1 week of preculture in G10, the islets were cultured for $18 \mathrm{~h}$ in the presence of G2, G5, G10, G30 or $\mathrm{G} 10+1 \mu \mathrm{mol} / 1$ thapsigargin. a-c XBP1, GADD153, ATF4, BiP and ACTIN protein levels were measured by western blot as described under Materials and methods and expressed relative to the level measured in islets cultured in G10. Key: (b) XBP1, open bars;

insulin secretion and the level of Xbpl mRNA splicing were low. Upon stimulation with G30, the increase in insulin secretion rate and $X b p l$ mRNA splicing were maximal within $2 \mathrm{~h}$ (Fig. 3a,b). In comparison, BiP and Grp94 mRNA levels did not increase before 4-8 h post stimulation, while Edem mRNA levels only rose after $24 \mathrm{~h}$ in G30 (data not shown). Conversely, in the reverse protocol, lowering glucose from G30 to G5 led to a rapid decline in insulin secretion and Xbpl mRNA splicing (Fig. 3c,d).

Time-dependence of the effects of glucose on the ISR We also tested the kinetics of ISR regulation by glucose. After culture in G10, lowering glucose to G2 triggered a rapid increase in Gadd153 mRNA levels (Fig. 4a). Under these conditions, $2 \mathrm{~h}$ of culture in G2 increased eIF $2 \alpha-\operatorname{Ser}^{51}$ phosphorylation to a lesser extent than addition of $10^{-6} \mathrm{~mol} / 1$ thapsigargin in $\mathrm{G} 10$, whereas culture in G5 and G30 had no effect (Fig. 4b). Interestingly, eIF2 $\alpha$ phosphorylation was never below detection limit in the present study, even after culture in G10 (also [20]). These results confirm that lowering glucose from G10 to G2 acutely induces the ISR. To further document the opposite effects of glucose on islet UPR and ISR, we also measured Gadd153 mRNA levels and eIF $2 \alpha-\mathrm{Ser}^{51}$ phosphorylation under conditions leading to a rapid increase in $X b p 1$ mRNA
GADD153, filled bars; (c) ATF4, open bars; BiP, filled bars; ACTIN, hatched bars. d-f, GADD153 was immunodetected on sections of islets cultured for $18 \mathrm{~h}$ in G2 (d), G10 (e) or G10 + thapsigargin (f). Results are representative $(\mathbf{a}, \mathbf{d}-\mathbf{f})$ or means $\pm \operatorname{SEM}(\mathbf{b}, \mathbf{c})$ for three to four experiments. ${ }^{*} p<0.05$ vs islets cultured in G10; $\# p<0.05$ for the effect of G30 vs G5 (one-way ANOVA +Newman-Keuls test). b, c Please note the logarithmic scales on the $y$-axes

splicing (see Fig. 3a,b). After $18 \mathrm{~h}$ culture in G5, stimulation with G30 led to a rapid decrease in Gadd153 mRNA levels (Fig. 4c). Under these conditions, the ratio of phosphorylated : total eIF $2 \alpha$ was significantly reduced by $2 \mathrm{~h}$ culture in G30 vs G5 and increased by $2 \mathrm{~h}$ treatment with thapsigargin (Fig. 4d). The clear parallel between glucose-induced early changes in islet eIF $2 \alpha$ phosphorylation and Gadd153 mRNA levels under these various conditions supports the hypothesis that culture in low glucose induces eIF $2 \alpha$ phosphorylation and downstream activation of the ISR.

Role of mitochondrial metabolism, $\mathrm{Ca}^{2+}$ influx and insulin secretion Glucose stimulation of beta cells increases glycolysis and mitochondrial metabolism, leading to a rise in cytosolic ATP:ADP ratio, subsequent closure of ATPdependent $\mathrm{K}^{+}$channels, plasma membrane depolarisation and opening of voltage-dependent $\mathrm{Ca}^{2+}$ channels. The resulting increase in cytosolic $\mathrm{Ca}^{2+}$ concentration is the triggering signal for exocytosis [10]. Except for changes in glycolysis, these stimulus-secretion coupling events can be elicited by various mitochondrial substrates in the presence of a non-stimulatory glucose concentration [29, 30]. As shown in Table 1, addition of a combination of $5 \mathrm{mmol} / 1$ leucine and $5 \mathrm{mmol} / 1$ glutamine, $10 \mathrm{mmol} / 1 \mathrm{SAM}$ or $5 \mathrm{mmol} / \mathrm{l} \mathrm{KIC}$ to G5 stimulated insulin secretion and $\mathrm{Xbp} 1$ 
a

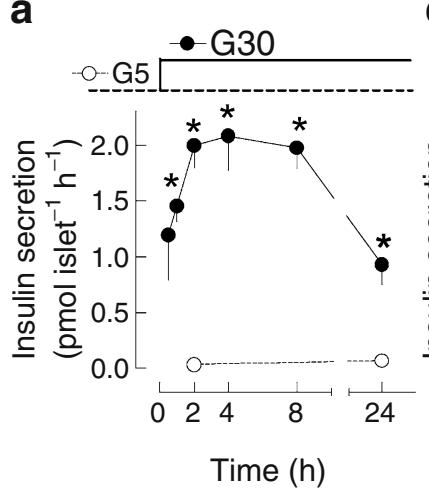

C

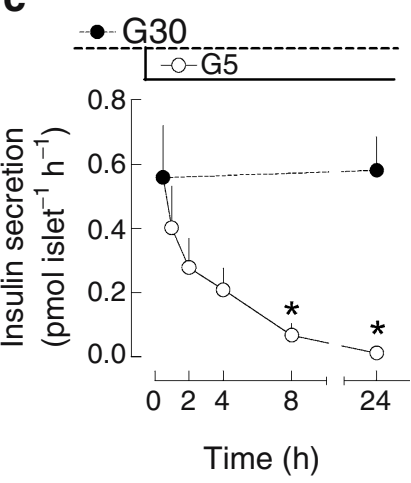

b

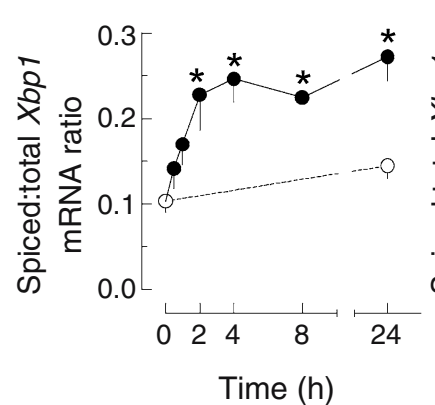

d

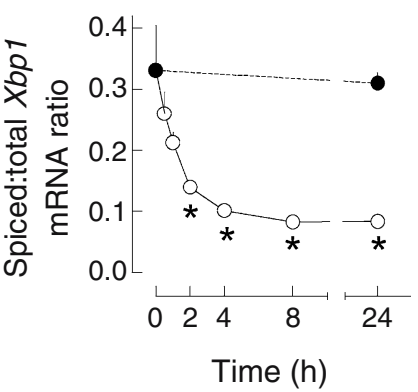

Fig. 3 Kinetics of glucose-induced changes in insulin secretion (a, c) and spliced : total $X b p 1$ mRNA ratio $(\mathbf{b}, \mathbf{d})$ in islets precultured for 1 week. a, b The islets were cultured for $18 \mathrm{~h}$ in G5 before being cultured in G5 (open symbols) or G30 (closed symbols) for 30 min up to $24 \mathrm{~h}$. c, d The islets were cultured for $18 \mathrm{~h}$ in G30 before being cultured in G30 (closed symbols) or G5 (open symbols). The rate of insulin secretion was calculated over the whole culture period of each sample. Data are means \pm SEM for three to four experiments. ${ }^{*} p<0.05$ or less vs G5 $(\mathbf{a}, \mathbf{b})$ or G30 (c, d) (one-way ANOVA + Dunnett's test)

mRNA splicing while reducing Gadd153 mRNA expression, SAM and KIC being as effective as G10. Thus, the effects of glucose on islet UPR and ISR are reproduced by various metabolic substrates that bypass glycolysis.

To evaluate the role of plasma membrane depolarisation, stimulation of $\mathrm{Ca}^{2+}$ influx and insulin secretion, we tested the effects of diazoxide, a drug that reduces $\mathrm{Ca}^{2+}$ influx and insulin secretion by opening ATP-dependent $\mathrm{K}^{+}$channels [10]. As expected, addition of diazoxide to G10 and G30 significantly reduced insulin secretion. However, it did not alter Xbp1 mRNA splicing or Gadd153 mRNA levels (Table 1). Similar results were obtained when insulin secretion was inhibited by clonidine, an $\alpha_{2}$-adrenergic agonist that inhibits cAMP production [31] and uncouples exocytosis from the rise in cytosolic $\mathrm{Ca}^{2+}$ concentration [32] (data not shown). Thus, glucose activates the UPR and reduces the ISR independently of its effects on beta cell membrane potential, $\mathrm{Ca}^{2+}$ influx and insulin secretion.

Role of protein synthesis Acceleration of mitochondrial metabolism by glucose and other metabolic substrates rapidly stimulates beta cell protein synthesis with a preferential effect on proinsulin [33, 34]. To investigate the role of changes in ER client protein load in the glucose regulation of the UPR and ISR, we tested the effect of cycloheximide, an inhibitor of protein synthesis. Under control conditions, islet protein synthesis was markedly increased between G2 and G10 and slightly decreased between G10 and G30 (Fig. 5a). Cycloheximide dosedependently inhibited protein synthesis in G10 with a halfmaximal effective concentration of $\sim 0.1 \mu \mathrm{mol} / 1$ (data not shown). At that concentration, cycloheximide did not affect islet protein synthesis in G2, but reduced it in G5, G10 and G30 (Fig. 5a). This attenuation of the glucose stimulation of protein synthesis completely prevented the glucose stimulation of Xbpl mRNA splicing, as well as BiP, Grp94 and Edem mRNA expression (Fig. 5c-f), but affected neither glucose-induced insulin secretion (Fig. 5b), nor glucose-induced reduction in Atf3, Gadd153 and Gadd34 mRNA levels (Fig. 5g,h; also data not shown). In contrast, cycloheximide failed to reduce the stimulation of Xbp1 mRNA splicing triggered by thapsigargin in G10, while completely preventing the increase in BiP mRNA levels (ESM Fig. 2a,b). After 1 day of culture in G5, cycloheximide also completely prevented the stimulation of Xbp 1 mRNA splicing triggered by $2 \mathrm{~h}$ culture in G30, without counteracting the reduction in Gadd153 mRNA levels (ESM Fig. 2c,d). Thus, reducing the glucose stimulation of protein synthesis, and hence of ER protein load, abrogates the glucose stimulation of islet UPR while leaving the reduction of the ISR unaffected.

\section{Discussion}

This study demonstrates that stimulation of isolated rat islets with glucose and other nutrients induces a rapid and sustained activation of the UPR, the maximal intensity of which is less than that induced by $10^{-7} \mathrm{~mol} / 1$ thapsigargin. Thus, like thapsigargin, glucose rapidly increases $X b p l$ mRNA splicing (a specific marker of IRE1 and UPR activation [19]) and XBP1 protein levels without increasing total $X b p 1$ mRNA levels. This effect is unrelated to the stimulation of $\mathrm{Ca}^{2+}$ influx and insulin secretion, but is likely to result from the stimulation of protein synthesis in beta cells. Thus, glucose-induced UPR activation was unaffected by diazoxide or clonidine, but was abrogated by cycloheximide at a concentration that did not suppress protein synthesis, only preventing its stimulation by glucose (Fig. 5a). Although the cycloheximide-mediated reduction in mRNA levels of UPR-responsive genes (BiP, Grp94 and Edem) may result from reduced synthesis of UPR transcription factors, the decrease in Xbpl mRNA splicing can 
Fig. 4 Acute effects of glucose on Gadd153 mRNA levels (a, c) and eIF $2 \alpha$-Ser ${ }^{51}$ phosphorylation $(\mathbf{b}, \mathbf{d})$ in islets precultured for 1 week. After preculture in $\mathrm{G} 10$, the islets were cultured in G10 (closed squares) or G2 (open squares) for $30 \mathrm{~min}$ up to $24 \mathrm{~h}$ (a) or for $2 \mathrm{~h}$ in G2, G5, $\mathrm{G} 10, \mathrm{G} 30$ or $\mathrm{G} 10+$

$1 \mu \mathrm{mol} / 1$ thapsigargin (TG)

(b). c, $\mathbf{d}$ The islets were cultured for $18 \mathrm{~h}$ in $\mathrm{G} 5$ before being cultured in G5 (open circles) or G30 (closed circles) for $30 \mathrm{~min}$ up to $24 \mathrm{~h}$ (c) or for $2 \mathrm{~h}$ in G5, $\mathrm{G} 30$ or G5 $+1 \mu \mathrm{mol} / 1$ thapsigargin (d). Gadd153:Tbp mRNA ratios are expressed relative to the ratio measured in islets at time 0 . The levels of phosphorylated (eIF $\left.2 \alpha^{\mathrm{P}}\right)$ and total eIF $2 \alpha\left(\mathrm{eIF} 2 \alpha^{\text {total }}\right)$ protein were measured by western blot and the ratio eIF $2 \alpha^{\text {P:total }}$ was expressed relative to the mean ratio in G10 (b) or G5 (d).

Results are means \pm SEM for three to four experiments. $* * p<0.01$ vs islets cultured in G10 (a, b) or G5 (c, d)(one-way ANOVA + Newman-Keuls test) a

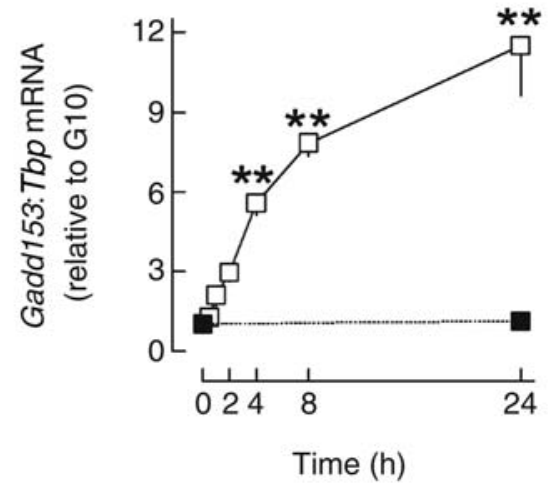

b
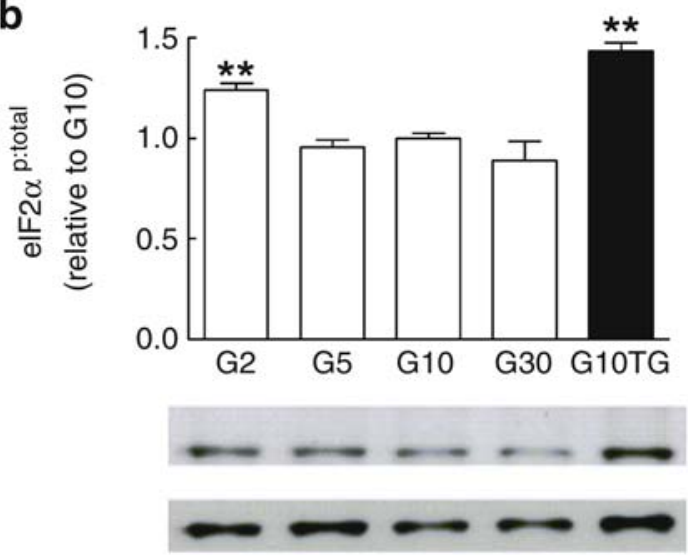

c

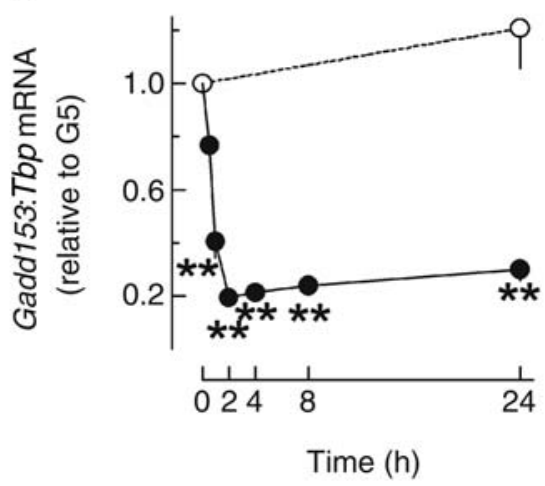

d

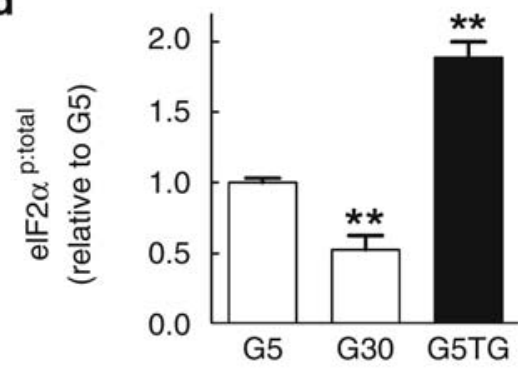

elF $2 \alpha^{p}$

elF2 $\alpha^{\text {total }}$
Table 1 Effects of mitochondrial metabolic substrates and diazoxide on insulin secretion during culture, Xbpl mRNA splicing and Gadd153 mRNA expression in cultured rat islets

\begin{tabular}{llll}
\hline & $\begin{array}{l}\text { Insulin secretion } \\
\left(\text { pmol islet }{ }^{-1} \mathrm{~h}^{-1}\right)\end{array}$ & $\begin{array}{l}\text { Spliced:total } \\
\text { Xbpl mRNA } \\
\text { ratio }\end{array}$ & $\begin{array}{l}\text { Gadd153:Tbp } \\
\text { mRNA ratio } \\
\text { (relative to } \\
\text { G10) }\end{array}$ \\
\hline G5 & $0.045 \pm 0.007$ & $0.10 \pm 0.01$ & $8.46 \pm 1.16$ \\
G5 + Leu-Gln & $0.356 \pm 0.046^{*}$ & $0.15 \pm 0.01 *$ & $2.72 \pm 0.19^{*}$ \\
G5 + SAM & $0.401 \pm 0.107^{*}$ & $0.21 \pm 0.03^{*}$ & $1.20 \pm 0.17^{*}$ \\
G5 + KIC & $0.455 \pm 0.084^{*}$ & $0.19 \pm 0.01^{*}$ & $1.51 \pm 0.13^{*}$ \\
G10 & $0.350 \pm 0.069^{*}$ & $0.20 \pm 0.01^{*}$ & $1.00 \pm 0.09^{*}$ \\
G10 + DZ & $0.067 \pm 0.007^{*}$ & $0.21 \pm 0.01$ & $0.62 \pm 0.04$ \\
G30 & $0.582 \pm 0.059^{*}$ & $0.30 \pm 0.01 *$ & $1.86 \pm 0.22^{*}$ \\
G30 + DZ & $0.250 \pm 0.034^{* *}$ & $0.33 \pm 0.03^{*}$ & $1.47 \pm 0.23$ \\
\hline
\end{tabular}

After 1 week preculture in G10, the islets were cultured for $18 \mathrm{~h}$ in G5, G10 or G30, with some groups also cultured in the presence of a combination of $5 \mathrm{mmol} / \mathrm{l}$ leucine and $5 \mathrm{mmol} / \mathrm{l}$ glutamine (Leu-Gln), $10 \mathrm{mmol} / 1 \mathrm{SAM}, 5 \mathrm{mmol} / 1 \mathrm{KIC}$ or $50 \mu \mathrm{mol} / 1$ diazoxide (DZ), as indicated. Gadd153 : Tbp mRNA ratios are expressed relative to the ratio in islets cultured in G10. There were no significant changes in $T b p$ and total $X b p 1$ mRNA levels. Data are means \pm SEM for three to six experiments.

$* p<0.05$ vs islets cultured in $\mathrm{G} 5 ; * * p<0.05$ for the effect of DZ in G10 or G30 (one-way ANOVA + Newman-Keuls test). unambiguously be attributed to a reduction in IRE1 activity upon inhibition of protein synthesis. Thus, cycloheximide fails to inhibit Xbpl mRNA splicing in response to thapsigargin treatment, indicating that IRE1, when adequately stimulated, is still able to splice $X b p 1$ pre-mRNA in cycloheximide-treated islets. Our results therefore strongly suggest that activation of the UPR by high glucose results from an increase in ER client protein load (Fig. 6b). The observation that $X b p 1 \mathrm{mRNA}$ splicing never reaches zero even after culture at low glucose suggests that the basal rate of protein synthesis in G2 is sufficient to slightly activate the UPR in cultured rat islets.

Our results slightly contrast with a recent study showing that glucose increases IRE $1 \alpha$ phosphorylation and expression of genes involved in UPR without increasing Xbpl mRNA splicing in isolated mouse islets [18]. This discrepancy is unlikely to be due to species differences, because glucose also increases $X b p 1$ mRNA splicing in mouse islets under our culture conditions (unpublished observations, M. Bensellam). It may rather result from the use of freshly isolated vs precultured islets, since $X b p 1$ mRNA splicing was significantly higher in fresh vs cultured rat islets (spliced : total $X b p 1$ mRNA ratio $0.55 \pm$ 0.02 in fresh islets vs $0.20 \pm 0.01$ in islets precultured for 1 week; $n=21-28 ; p<0.0001$ by unpaired $t$ test). This high 
a

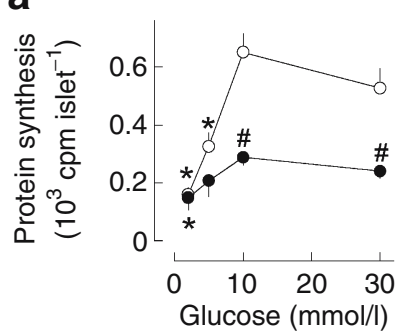

C

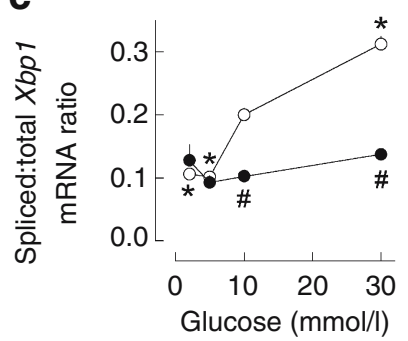

e

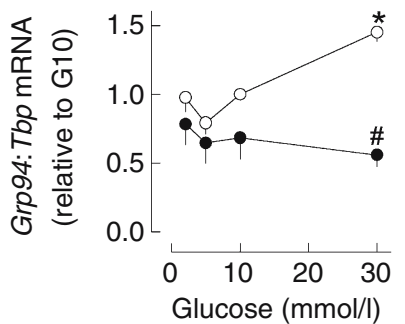

g

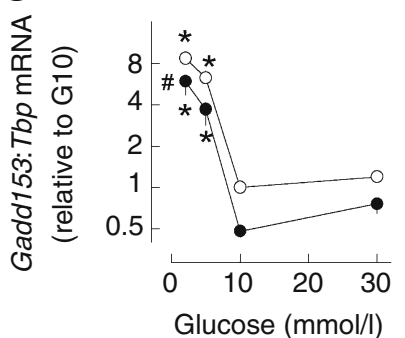

b

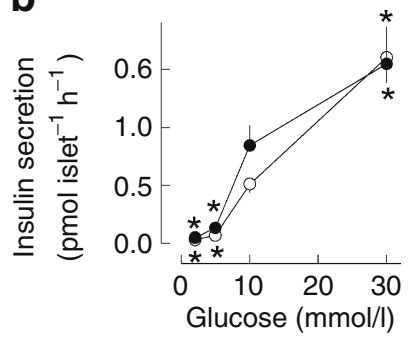

d

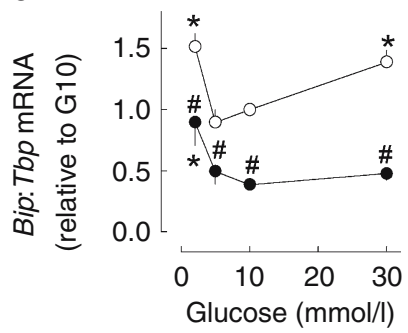

f

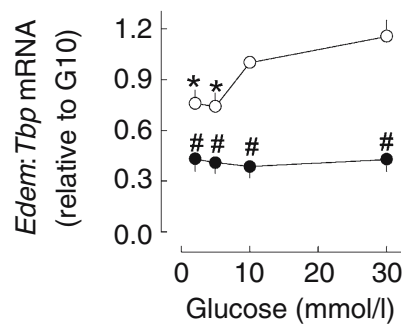

h

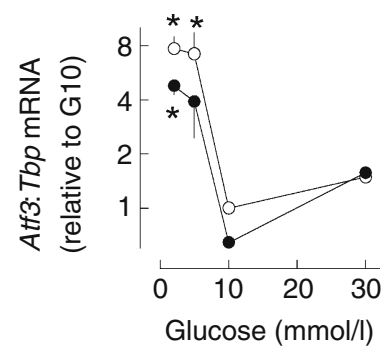

Fig. 5 Effects of cycloheximide on glucose-induced changes in total protein synthesis (a), insulin secretion during culture (b), spliced : total Xbp1 mRNA ratio (c) and BiP, Grp94, Edem, Gadd153 and Atf3 mRNA levels $(\mathbf{d}-\mathbf{h})$ in isolated rat islets. After 1 week of preculture in G10, the islets were cultured for $18 \mathrm{~h}$ in G2, G5, G10 or G30 without (open circles) or with cycloheximide $0.1 \mu \mathrm{mol} / 1$ (closed circles). Gene:Tbp mRNA ratios are expressed relative to the ratio in islets cultured in G10. Data are means \pm SEM for three to four experiments. ${ }^{*} p<0.05$ for the effects of glucose vs G10 in the presence or absence of cycloheximide; ${ }^{*} p<0.05$ for the effect of cycloheximide under the same condition (Two-way ANOVA + Bonferroni's test). $\mathbf{g}-\mathbf{h}$ Please note the logarithmic scales on the y-axes

level of Xbpl mRNA splicing, which may result from the stress of isolation, was observed regardless of the preisolation condition, thereby preventing us from studying the impact of in vivo hyperglycaemia on UPR activation.

What could be the physiological role of nutrientactivation of the UPR in islet beta cells? Its rapid onset upon glucose stimulation and fast reduction upon lowering of glucose concentration suggest that meal-related fluctua-

tions in plasma nutrient concentration may induce synchronous fluctuations of $X b p 1$ mRNA splicing and other early steps of the UPR in beta cells. By adapting the ER chaperone to client protein ratio and the ER-associated degradation capacity to physiological variations in protein synthesis, temporal integration of these UPR fluctuations could contribute to the plasticity of the beta cell phenotype [35]. Our hypothesis may seem at variance with the observation, by electron microscopy, of normal beta cells in Xbpl knockout mice with a liver-specific rescue of Xbpl expression [36]. However, the argument is not sufficient to exclude a role for XBP1 in beta cell plasticity for several reasons. First, because apolipoprotein E mRNA is expressed in rat islets (unpublished observations, M. Bensellam), expression of Xbpl under the apolipoprotein E promoter may have corrected XBP1 deficiency not only in the liver but also in beta cells. Second, beta cell function was not evaluated in that study, leaving open the possibility that beta cells were defective in those mice despite their normal morphology. Third, it is possible that XBP1 is not important in the early post-natal period, but becomes so later in life, when beta cells are more responsive to nutrient stimulation.

Although we had expected the ISR to be activated by nutrients in parallel with $X b p 1$ mRNA splicing, as after thapsigargin treatment, we unexpectedly observed a partial dissociation between both responses. Thus, the UPR was low in G2-G5 and concentration-dependently activated by G10 and G30, whereas the ISR was high in G2, minimal (though not zero) in G10 and slightly increased in G30, as shown by changes in eIF $2 \alpha$ phosphorylation, ATF 4 protein levels and ATF4-target gene mRNA levels. It has also been recently shown in MIN6 cells that low glucose strongly induces the ISR in beta cells [21]. As there were no detectable increases in eIF $2 \alpha$ phosphorylation and ATF4 production in G5 vs G10, the rise in ATF4-target gene mRNA levels in G5 may have resulted from their transcriptional activation by a mechanism different from the ISR and from their concomitant stabilisation. However, our interpretation that the ISR is activated in G5 is supported by the observations that eIF $2 \alpha$ phosphorylation rapidly decreases upon stimulation from G5 to G30 in rat islets (see Fig. 4d) and within the whole physiological range of glucose concentrations in MIN6 cells [20, 37].

It was not our primary aim to investigate the mechanism of ISR activation in low glucose. Nevertheless, our results clearly demonstrate that ISR activation can be prevented or acutely reduced by stimulation with glucose (and SAM, $\mathrm{KIC}$ and leucine + glutamine) independently of the stimulation of $\mathrm{Ca}^{2+}$ influx, insulin secretion and protein synthesis. It could result either from the activation of any eIF2 $\alpha$ kinase, among which PERK and EIF2AK4 are the most likely candidates [11], or by the inactivation of protein 
a

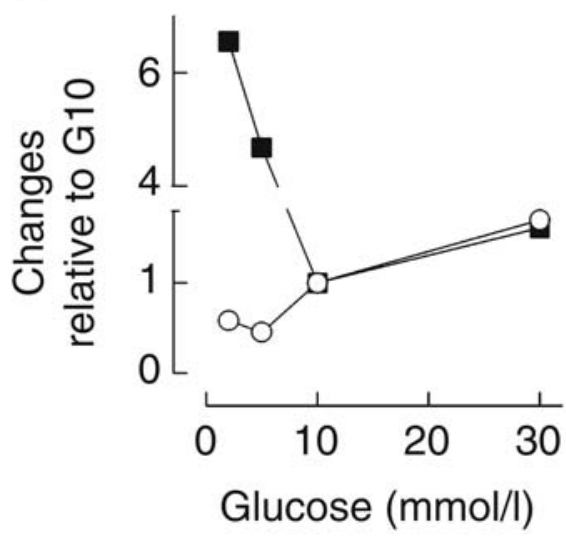

b

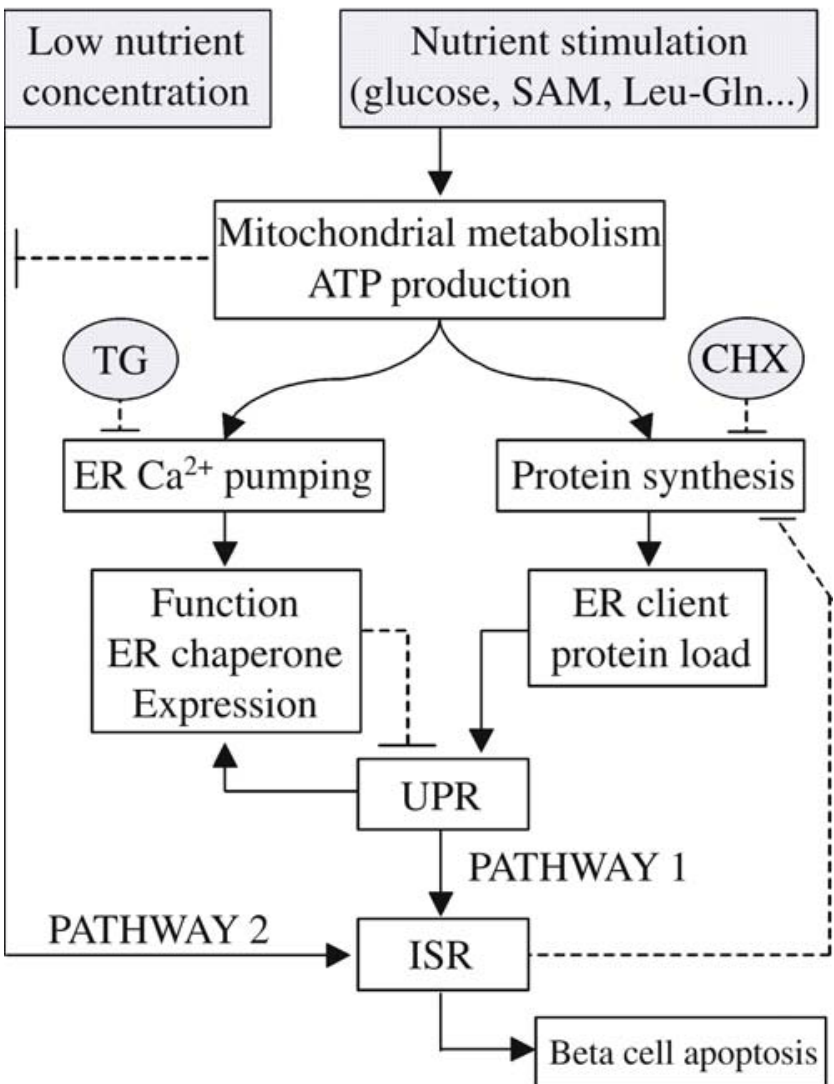

Fig. 6 Nutrient regulation of the mRNA levels of genes involved in the UPR and ISR in pancreatic beta cells. a Glucose-induced changes in Xbpl mRNA splicing (UPR, open circles) and average changes in Atf3, Gadd153 and Gadd34 mRNA levels (ISR, closed squares) relative to their level after culture in G10 (normalised data from Fig. 1d and h). b Proposed model (for explanation see Discussion). Unbroken line with arrow, stimulation; dashed line with lateral symbol, inhibition

phosphatase 1 , mediated by inhibitor-1, which is highly expressed in beta cells [20]. In other cell types, complete glucose deprivation is known to induce the UPR, an effect generally attributed to ER $\mathrm{Ca}^{2+}$ emptying and reduced ER chaperone function at very low ATP concentrations $[1,3]$. However, the situation was clearly different in G2-G5, where the islet ATP:ADP ratio is only moderately reduced as compared with G10 [27, 38] and Xbpl mRNA splicing was not increased.

Although we did not fully investigate the mechanisms behind the asymmetric V-shaped glucose-concentration response curve for changes in expression of genes involved in islet ISR, our results allow us to propose the following model. On the one hand, the ISR is activated in parallel with nutrient activation of the classical UPR (pathway 1, Fig. 6b), as shown by the parallel increases in Xbp1 mRNA splicing and in mRNA levels of genes involved in UPR and ISR between G10 and G30. This ISR activation is very low, as neither eIF $2 \alpha$ phosphorylation nor an increase in ATF4 or GADD153 protein expression could be detected in G30 vs G10. The 1.6-fold increase in ATF4-target gene mRNA levels in G30 vs G10 is, however, compatible with our estimation (based on changes in Xbpl mRNA splicing) that the maximal glucose activation of the UPR is less than that produced by $10^{-7} \mathrm{~mol} / \mathrm{l}$ thapsigargin. On the other hand, low glucose concentrations (G2 and G5 vs G10) rapidly increase mRNA levels of genes involved in ISR by inducing their transcription and, to some extent, increasing their mRNA stability (pathway 2, Fig. 6b). The reduction in mRNA of genes involved in ISR and in corresponding protein levels between G5 and G10, despite concurrent activation of the UPR, therefore indicates that, within that physiological range of glucose concentrations, pathway 2 predominates over pathway 1 for regulation of the ISR (Fig. 6b).

What could be the role of the asymmetric V-shaped glucose concentration-dependent changes in ISR in islet beta cells? In the short term, changes in eIF $2 \alpha$ phosphorylation may play a role in the nutrient regulation of protein synthesis [12, 14, 20, 37]. This hypothesis is compatible with our finding of an inverse correlation between glucoseinduced changes in mRNA levels of genes involved in islet ISR and total protein synthesis after $18 \mathrm{~h}$ culture. It is strongly supported by the observation that inhibiting glucose-induced eIF $2 \alpha$ de-phosphorylation markedly reduced the acute glucose stimulation of protein synthesis in MIN6 cells [20]. In the long term, beta cell apoptosis after 2-7 days of culture also displayed a V-shaped glucose concentration-dependent curve $[27,28,39,40]$. We, in fact, confirmed, by measuring caspase activation, that islet cell apoptosis is minimal after 1 week of culture in G10 and significantly increased by G2-G5 and, to a lesser extent, by G30 (ESM Fig. 3). The rather good correlation between rapid ISR activation and slower induction of apoptosis reinforces the hypothesis of a causal link between both events under various conditions $[13,41]$. Thus, although the activation of islet ISR and apoptosis by G30 vs G10 was rather small in comparison to that induced by low glucose, the sustained activation of the islet UPR by G30 is 
compatible with recent studies indicating that prolonged exposure to high glucose or high NEFA concentrations induces an ER stress response that may contribute to the slow deterioration of beta cell function and survival in type 2 diabetes [15-17, 42, 43]. In this context, it will be crucial to clarify whether ISR activation contributes to beta cell apoptosis [13, 41, 44], protects against it $[45,46]$ or is just a marker of beta cell exposure to pro-apoptotic stimuli.

In conclusion, our results demonstrate that nutrient stimulation of rat islets moderately activates the classical UPR in a manner dependent on protein synthesis and inhibits the strongly increased expression, induced by low glucose concentrations, of genes involved in ISR. Both effects lead to an asymmetric V-shaped glucose-concentration response curve for changes in islet ISR. The kinetics of these effects suggests their possible role in nutrient-induced changes of the beta cell phenotype under both physiological and pathological conditions.

Acknowledgements The authors thank A. Dannau and F. Knockaert for expert technical help and D. Scheuner (University of Michigan, Ann Arbor, MI, USA) for supply of the eIF $2 \alpha$ antiserum. This work was made possible by a grant from the European Foundation for the Study of Diabetes/MSD Research Partnership for European Studies on beta cell function and survival. It was supported by Grant 1.5.182.04 from the Fonds de la Recherche Scientifique (Scientific Research Foundation; FRS-FNRS, Belgium), Grants 3.4616.05 and 3.4506.05 from the Fonds de la Recherche Scientifique Médicale (Medical Research Foundation, Belgium), the Interuniversity Poles of Attraction Program (P5/17)Belgian Science Policy, Grant ARC 05/10-328 from the General Direction of Scientific Research of the French Community of Belgium and Grant (GOA/2004/11) from the Catholic University of Leuven (to F. C. Schuit). M. Bensellam is Research Fellow and J. C. Jonas is Senior Research Associate of the FRS-FNRS (Belgium).

Duality of interest The authors have no duality of interest to disclose.

\section{References}

1. Fink AL (1999) Chaperone-mediated protein folding. Physiol Rev 79:425-449

2. Ma Y, Hendershot LM (2004) ER chaperone functions during normal and stress conditions. J Chem Neuroanat 28:51-65

3. Schroder M, Kaufman RJ (2005) The mammalian unfolded protein response. Annu Rev Biochem 74:739-789

4. Marciniak SJ, Ron D (2006) Endoplasmic reticulum stress signaling in disease. Physiol Rev 86:1133-1149

5. Lee AH, Iwakoshi NN, Glimcher LH (2003) XBP-1 regulates a subset of endoplasmic reticulum resident chaperone genes in the unfolded protein response. Mol Cell Biol 23:7448-7459

6. Lu PD, Harding HP, Ron D (2004) Translation reinitiation at alternative open reading frames regulates gene expression in an integrated stress response. J Cell Biol 167:27-33

7. Ma Y, Hendershot LM (2004) Herp is dually regulated by both the endoplasmic reticulum stress-specific branch of the unfolded protein response and a branch that is shared with other cellular stress pathways. J Biol Chem 279:13792-13799
8. Harding HP, Zhang Y, Zeng H et al (2003) An integrated stress response regulates amino acid metabolism and resistance to oxidative stress. Mol Cell 11:619-633

9. Jiang HY, Wek SA, McGrath BC et al (2004) Activating transcription factor 3 is integral to the eukaryotic initiation factor 2 kinase stress response. Mol Cell Biol 24:1365-1377

10. MacDonald PE, Joseph JW, Rorsman P (2005) Glucose-sensing mechanisms in pancreatic $\beta$-cells. Philos Trans R Soc Lond, B Biol Sci 360:2211-2225

11. Scheuner D, Song B, McEwen E et al (2001) Translational control is required for the unfolded protein response and in vivo glucose homeostasis. Mol Cell 7:1165-1176

12. Harding HP, Zeng H, Zhang Y et al (2001) Diabetes mellitus and exocrine pancreatic dysfunction in Perk $-/-$ mice reveals a role for translational control in secretory cell survival. Mol Cell 7:1153-1163

13. Oyadomari S, Koizumi A, Takeda K et al (2002) Targeted disruption of the Chop gene delays endoplasmic reticulum stress-mediated diabetes. J Clin Invest 109:525-532

14. Scheuner D, Vander Mierde D, Song B et al (2005) Control of mRNA translation preserves endoplasmic reticulum function in beta cells and maintains glucose homeostasis. Nat Med 11:757-764

15. Kharroubi I, Ladriere L, Cardozo AK, Dogusan Z, Cnop M, Eizirik DL (2004) Free fatty acids and cytokines induce pancreatic $\beta$-cell apoptosis by different mechanisms: role of NF- $\mathrm{KB}$ and endoplasmic reticulum stress. Endocrinology 145:5087-5096

16. Wang H, Kouri G, Wollheim CB (2005) ER stress and SREBP-1 activation are implicated in $\beta$-cell glucolipotoxicity. J Cell Sci 118:3905-3915

17. Karaskov E, Scott C, Zhang L, Teodoro T, Ravazzola M, Volchuk A (2006) Chronic palmitate but not oleate exposure induces endoplasmic reticulum stress, which may contribute to INS-1 pancreatic $\beta$-cell apoptosis. Endocrinology 147:3398-3407

18. Lipson KL, Fonseca SG, Ishigaki S et al (2006) Regulation of insulin biosynthesis in pancreatic beta cells by an endoplasmic reticulum-resident protein kinase IRE1. Cell Metab 4:245-254

19. Calfon M, Zeng H, Urano $F$ et al (2002) IRE1 couples endoplasmic reticulum load to secretory capacity by processing the XBP-1 mRNA. Nature 415:92-96

20. Vander Mierde D, Scheuner D, Quintens R et al (2006) Glucose activates a PP1 mediated signaling pathway to enhance overall translation in pancreatic beta cells. Endocrinology 148:609-617

21. Greenman IC, Gomez E, Moore CE, Herbert TP (2007) Distinct glucose-dependent stress responses revealed by translational profiling in pancreatic $\beta$-cells. J Endocrinol 192:179-187

22. Jonas JC, Guiot Y, Rahier J, Henquin JC (2003) Haeme-oxygenase 1 expression in rat pancreatic $\beta$-cells is stimulated by supraphysiological glucose concentrations and by cyclic AMP. Diabetologia 46:1234-1244

23. Elouil H, Cardozo AK, Eizirik DL, Henquin JC, Jonas JC (2005) High glucose and hydrogen peroxide increase c-Myc and haemeoxygenase $1 \mathrm{mRNA}$ levels in rat pancreatic islets without activating NFKB. Diabetologia 48:496-505

24. Garcia-Barrado MJ, Ravier MA, Rolland JF, Gilon P, Nenquin M, Henquin JC (2001) Inhibition of protein synthesis sequentially impairs distinct steps of stimulus-secretion coupling in pancreatic $\beta$ cells. Endocrinology 142:299-307

25. Heding LG (1972) Determination of total serum insulin (IRI) in insulin-treated diabetic patients. Diabetologia 8:260-266

26. Jonas JC, Laybutt DR, Steil GM et al (2001) High glucose stimulates early response gene c-Myc expression in rat pancreatic $\beta$ cells. J Biol Chem 276:35375-35381

27. Khaldi MZ, Guiot Y, Gilon P, Henquin JC, Jonas JC (2004) Increased glucose sensitivity of both triggering and amplifying pathways of insulin secretion in rat islets cultured for one week in high glucose. Am J Physiol, Endocrinol Metab 287:E207-E217 
28. Van de Casteele M, Kefas BA, Cai Y et al (2003) Prolonged culture in low glucose induces apoptosis of rat pancreatic $\beta$-cells through induction of c-myc. Biochem Biophys Res Commun 312:937-944

29. Malaisse WJ, Sener A, Malaisse-Lagae F et al (1982) The stimulus-secretion coupling of amino acid-induced insulin release. Metabolic response of pancreatic islets of L-glutamine and Lleucine. J Biol Chem 257:8731-8737

30. Malaisse WJ, Rasschaert J, Villanueva-Penacarrillo ML, Valverde I (1993) Respiratory, ionic, and functional effects of succinate esters in pancreatic islets. Am J Physiol 264:E428-E433

31. Schuit FC, Pipeleers DG (1986) Differences in adrenergic recognition by pancreatic A and B cells. Science 232:875-877

32. Renstrom E, Ding WG, Bokvist K, Rorsman P (1996) Neurotransmitter-induced inhibition of exocytosis in insulin-secreting $\beta$ cells by activation of calcineurin. Neuron 17:513-522

33. Ashcroft SJ, Bunce J, Lowry M, Hansen SE, Hedeskov CJ (1978) The effect of sugars on (pro)insulin biosynthesis. Biochem $\mathrm{J}$ 174:517-526

34. Schuit FC, In't Veld PA, Pipeleers DG (1988) Glucose stimulates proinsulin biosynthesis by a dose-dependent recruitment of pancreatic beta cells. Proc Natl Acad Sci USA 85:3865-3869

35. Hinke SA, Hellemans K, Schuit FC (2004) Plasticity of the $\beta$ cell insulin secretory competence: preparing the pancreatic $\beta$ cell for the next meal. J Physiol 558:369-380

36. Lee AH, Chu GC, Iwakoshi NN, Glimcher LH (2005) XBP-1 is required for biogenesis of cellular secretory machinery of exocrine glands. EMBO J 24:4368-4380

37. Gomez E, Powell ML, Greenman IC, Herbert TP (2004) Glucosestimulated protein synthesis in pancreatic $\beta$-cells parallels an increase in the availability of the translational ternary complex (eIF2-GTP.Met-tRNAi) and the dephosphorylation of eIF2 $\alpha$. J Biol Chem 279:53937-53946
38. Detimary P, Jonas JC, Henquin JC (1995) Possible links between glucose-induced changes in the energy state of pancreatic B cells and insulin release. Unmasking by decreasing a stable pool of adenine nucleotides in mouse islets. J Clin Invest 96:1738-1745

39. Hoorens A, Van de Casteele M, Klöppel G, Pipeleers DG (1996) Glucose promotes survival of rat pancreatic $\beta$ cells by activating synthesis of proteins which suppress a constitutive apoptotic program. J Clin Invest 98:1568-1574

40. Efanova IB, Zaitsev SV, Zhivotovsky B et al (1998) Glucose and tolbutamide induce apoptosis in pancreatic $\beta$-cells - a process dependent on intracellular $\mathrm{Ca}^{2+}$ concentration. J Biol Chem 273:33501-33507

41. Cardozo AK, Ortis F, Storling J et al (2005) Cytokines downregulate the sarcoendoplasmic reticulum pump $\mathrm{Ca}^{2+}$ ATPase $2 \mathrm{~b}$ and deplete endoplasmic reticulum $\mathrm{Ca}^{2+}$, leading to induction of endoplasmic reticulum stress in pancreatic $\beta$-cells. Diabetes 54:452-461

42. Cnop M, Welsh N, Jonas JC, Jorns A, Lenzen S, Eizirik DL (2005) Mechanisms of pancreatic $\beta$-cell death in type 1 and type 2 diabetes: many differences, few similarities. Diabetes 54(Suppl 2): S97-S107

43. Laybutt DR, Preston AM, Akerfeldt MC et al (2007) Endoplasmic reticulum stress contributes to beta cell apoptosis in type 2 diabetes. Diabetologia 50:752-763

44. Hartman MG, Lu D, Kim ML et al (2004) Role for activating transcription factor 3 in stress-induced $\beta$-cell apoptosis. Mol Cell Biol 24:5721-5732

45. Boyce M, Bryant KF, Jousse C et al (2005) A selective inhibitor of eIF $2 \alpha$ dephosphorylation protects cells from ER stress. Science 307:935-939

46. Yusta B, Baggio LL, Estall JL et al (2006) GLP-1 receptor activation improves beta cell function and survival following induction of endoplasmic reticulum stress. Cell Metab 4:391-406 